\title{
OS CONTORNOS POSSÍVEIS DO DISCURSO DE ÓDIO NO BRASIL: PROPOSTA A PARTIR DA CONVENÇÃO AMERICANA DE DIREITOS HUMANOS
}

\author{
THE POSSIBLE CONTOURS OF HATE SPEECH IN BRAZIL: \\ PROPOSAL FROM THE AMERICAN CONVENTION ON HUMAN \\ RIGHTS \\ Anna Luisa Walter de Santana ${ }^{1}$ \\ Danielle Anne Pamplona ${ }^{1}$
}

Recebido em: 03/05/2018 Aceito em: 30/09/2018

annaluisasantana@hotmail.com dapamplona@pamplonaebraz.com.br
Resumo: O texto tem como objetivo apresentar uma possibilidade de restrição à liberdade de expressão, no Brasil, a partir dos instrumentos internacionais aplicáveis ao país. Trata-se de identificar, se existentes, contornos para a aplicação das regras sobre o discurso de ódio. Para isso, parte da avaliação de seu conteúdo com base na ideia de tolerância como proposta por Bobbio. Avalia os instrumentos internacionais onusianos e interamericanos que contêm disposições sobre o assunto e manifestações das Relatorias Especiais para Liberdade de Expressão e da Corte Interamericana de Direitos Humanos. Ao final, conclui que o Brasil pode se utilizar das disposições da Convenção sobre a extensão e aplicação dos direitos e restrições que ela contem, em especial as que buscam no regime democrático os contornos dos direitos. Com isso, o Brasil formatará, na decisão de casos concretos, a democracia que quer construir, estabelecendo os limites que se impõem também à restrição de direitos humanos.

Palavras-chave: Discurso de ódio. Liberdade de expressão. Tolerância.

\begin{abstract}
The text aims to present a possibility of restricting freedom of expression in Brazil, based on international instruments applicable to the country. It is a question of identifying, if existing, contours for the application of rules on hate speech. In order to do so, it departs from the evaluation of its content based on the idea of tolerance as proposed by Bobbio. It evaluates the United Nations' and American's instruments which contain provisions on the subject and manifestations of the Special Rapporteurs for Freedom of Expression and the Inter-American Court of Human Rights. In the end, it concludes that Brazil can use the provisions of the Convention on the extension and application of the rights and restrictions that it contains, especially those that seek the contours of rights in the democratic regime. With this, Brazil will, in the adjudication process, shape the democracy that wants to build, establishing the limits that are also imposed to the restriction of human rights.
\end{abstract}

Keywords: Hate speech. Freedom of expression. Tolerance.

\section{INTRODUÇÃO}

Em 25 de setembro de 2015 a Organização das Unidas adotou formalmente a agenda 2030 para o desenvolvimento sustentável. O documento propõe 17 objetivos do Desenvolvimento Sustentável e 169 metas correspondentes, que serão implementados entre 2016-2030. A Agenda 2030 em sua declaração afirma que os Países-membros se comprometem a promover a compreensão intercultural, a tolerância, o respeito mútuo, e uma ética de cidadania global e responsabilidade compartilhada.

\footnotetext{
${ }^{1}$ Pontifícia Universidade Católica do Paraná - PUCPR - Curitiba - Paraná - Brasil
} 
O $16^{\circ}$ objetivo se propõe a promover sociedades pacíficas e inclusivas para 0 desenvolvimento sustentável e na alínea b reforça e necessidade de se fazer cumprir leis e políticas não discriminatórias.

Partindo desses compromissos, as causas que representam óbice ao desenvolvimento sustentável e ao sucesso dos objetivos da Agenda 2030 merecem destaque e atenção por parte da comunidade acadêmica.

O discurso de ódio, objeto de estudo desse artigo, representa a contramão de sociedades tolerantes e inclusivas, isto porque além do prejuízo causado a vítima ou as vítimas, reproduz preconceito, discriminação e enfraquece o espaço democrático.

No Brasil, especialmente, discutir e estabelecer parâmetros para o discurso de ódio é indispensável. Primeiro porque não existe uma legislação brasileira sobre o tema, segundo, a doutrina e escassa jurisprudência sobre o tema não trazem a caracterização clara do discurso de ódio e as medidas necessárias para seu combate.

Estudo da análise da jurisprudência brasileira sobre discurso de ódio realizado na FGV demonstrou que o Judiciário brasileiro é repressivo quanto a este tipo de manifestação, mas é a Lei 7716/89 chamada a balizar as decisões, ficando sem procedimento para as situações em que o ódio não se manifesta na questão racial, mas de gênero, idade, orientação sexual (SILVA, 20111)².

$\mathrm{Na}$ tentativa de se estabelecer critérios mais precisos para definição do discurso de ódio optou-se pela sua análise diante dos parâmetros estabelecidos pelo Sistema Interamericano, especialmente pelas recomendações e relatórios da Comissão Interamericana de Direitos Humanos, através de sua Relatoria Especial para a liberdade de expressão.

O Brasil, enquanto membro da OEA, e diante da vigência em território nacional desde 1992 da Convenção Interamericana de Direitos Humanos, assumiu o compromisso de acatar as recomendações dos órgãos que integram o sistema e de adotar as medidas necessárias ao fiel cumprimento das obrigações assumidas na proteção e promoção aos direitos humanos.

A Relatoria Especial para a liberdade de expressão, em 2015, dedicou capítulo especial em seu relatório anual para tratar do tema do discurso de ódio e recomendou aos Estados membros da OEA, entre outras iniciativas, que adotassem medidas jurídicas que combatessem o discurso de ódio e assegurassem que a legislação que sancionar o discurso se adeque de maneira expressa ao artigo 13.5 da Convenção e aos princípios estabelecidos pela Comissão, pela Corte e pelo direito internacional de direitos humanos.

Para tal análise, o artigo explora a necessidade de se impor limites à liberdade de expressão através de discussões teóricas sobre a tolerância e o pluralismo, inerentes às sociedades democráticas. Em seguida se dedica a compreender o entendimento do Sistema Interamericano do direito à liberdade de expressão e pensamento e suas possíveis limitações. Passando, ao final, à análise dos relatórios da Relatoria Especial para a liberdade de expressão sobre o discurso de ódio,

\footnotetext{
2 A organização Artigo 19 também possui relatório sobre o discurso de ódio no Brasil e reforça que apesar do número de denuncias ser significativo, existe pouquíssima jurisprudência sobre o tema e falta de parâmetros nas decisões. Artigo 19. Panorama sobre o discurso de ódio no Brasil. Disponível em: artigo19.org/centro/files/discurso_odio.pdf. Acesso em: 19 de julho de 2016.
} 
com vistas a encontrar uma definição precisa deste tipo de discurso, os requisitos necessários para sua configuração e as medidas recomendadas pela Relatoria e pela Comissão para seu combate.

\section{A EXTENSÃO DA TOLERÂNCIA E SUA RELAÇÃO COM O DISCURSO DE ÓDIO}

O contexto político e social do início do século XX é marcado pelo encurtamento das fronteiras e dos limites entre os Estados, o que nos leva a reflexão de temas caros às sociedades democráticas como a tolerância e o pluralismo. Ondas migratórias, refugiados de guerra e de clima, atentados terroristas, intolerância, preconceito, ocupam espaço nas discussões modernas e transcendem fronteiras nacionais.

A globalização transforma o cotidiano com uma violência inegável e representa a ação sem fronteiras nas dimensões da economia, das questões econômicas, ambientais, dos conflitos transculturais e da sociedade civil (BECK, 1999). O mundo globalizado desafia a humanidade a resolver os problemas que surgem da complexa rede de relações que liga os indivíduos; pessoas e grupos sociais profundamente diferentes se encontram e precisam construir um espaço adequado de convívio, tolerando e respeitando as diferenças.

Por certo a exigência da tolerância não nasce com os Estados globalizados, mas sua necessidade se intensifica de maneira profunda ${ }^{3}$. Bobbio afirma que a tolerância surge no terreno das controvérsias religiosas, no momento em que se toma consciência da irredutibilidade das opiniões e da necessidade de se encontrar um modo de conviverem. Trata-se do reconhecimento do igual direito a conviver que se reconhece a doutrinas opostas (BOBBIO, 2002).

Para Habermas (2002, p. 165 e 166) "naquilo que é relevante para seu caráter, pessoas são entroncamentos em uma rede adscritícia de culturas e tradições" e mesmo em uma comunidade republicana podem eclodir conflitos culturais. Isto porque, o problema das minorias, que pode surgir nas sociedades pluralistas, é ainda mais intensificado nas sociedades multiculturais.

A tolerância pode assumir um caráter plurívoco na visão de Walzer (1999), para quem seu conteúdo varia segundo os regimes políticos em que convivem diversos grupos sociais, sem que haja necessariamente um sentido progressivo entre eles. Nos Estados-Nações, em que um grupo organiza a vida da comunidade, a tolerância não contempla os grupos, mas participantes individuais que são concebidos como membros de alguma minoria e suas práticas devem passar pelo escrutínio da minoria. Já nas sociedades de imigrantes o Estado é neutro em relação aos grupos, tolerando a todos, a tolerância assume uma feição radicalmente descentralizada.

Já Wolf (1970), por sua vez, analisa a tolerância como uma virtude política, no sentido de ser o espírito que permite o melhor desempenho da democracia pluralista. Contudo, mesmo nas sociedades democráticas, uma cultura majoritária no comando das decisões políticas pode negar igualdade de direitos a uma minoria ao impor sua forma de vida e seus valores (HABERMAS, 2002).

A questão de fundo que se coloca em todos os teóricos que tratam da tolerância é a sua possibilidade de limitação. Até que ponto devemos tolerar os intolerantes? Aqui a discussão se torna

3 Nesse sentido Walzer afirma que após a Primeira Guerra houve um esforço para garantir a tolerância de minorias nacionais nos novos e radicalmente heterogêneos Estados-Nações (WALZER, 1999).

Revista do Direito [ISSN 1982-9957]. Santa Cruz do Sul, v. 2, n. 55, p. 13-30, maio/ago. 2018. https://online.unisc.br/seer/index.php/direito/index 
muito apropriada quando se propõe uma reflexão acerca dos discursos de ódio e os limites à liberdade de expressão.

Bobbio defende a tolerância como um bem em si, de modo que "todas as ideias devem ser toleradas, menos aquelas que negam a ideia mesma de tolerância" (2002, p. 153). Contudo, reforça que responder ao intolerante com intolerância, embora juridicamente lícito, não se apresenta como a melhor solução, pois dificilmente isso tornará o intolerante um liberal.

A solução para Bobbio (2002) é uma questão última, que não admite justificação exclusivamente racional. Dependendo do momento histórico vivido por cada comunidade, podem se justificar escolhas mais ou menos tolerantes com os grupos intolerantes, sendo que isso determinará se a comunidade adota um conceito extensivo de tolerância, próprio do liberalismo progressista, ou restritivo de tolerância, próprio do liberalismo conservador.

Ainda que se pense em uma solução a depender do momento histórico é preciso considerar que nas sociedades democráticas, espaço próprio da coexistência pacífica de opiniões e interesses plurais e conflitivos (CHÂTELET; DUHAMEL; PISIER-KOUCHER, 1985), é preciso encontrar uma mínima concordância sobre o que é tolerável ou intolerável.

Afinal, sociedades democráticas não podem permitir o preconceito e a discriminação, que minam a própria ideia de democracia e de ambiente plural.

Os Estados democráticos valorizam a liberdade de expressão como forma de manutenção desse espaço plural, mas proíbem, em maior ou menor medida, formas de comunicação marcadamente intolerantes com pessoas ou grupos (TSESIS, 2009). Conhecidos pela expressão em inglês hate speech, os discursos do ódio referem-se a palavras que "tendem a insultar, intimidar ou assediar pessoas em virtude de sua raça, cor, etnicidade, nacionalidade, sexo ou religião, ou que têm a capacidade de instigar violência, ódio ou discriminação contra tais pessoas" (BRUGGER, 2007, p. 118).

Discursos de ódio derivam do preconceito e levam à discriminação, afinal a principal consequência nociva do preconceito de grupo é a discriminação. A grande dificuldade de lidar com tais formas de expressão está na própria essência do conceito de preconceito, que deve ser entendido como uma opinião ou conjunto de opiniões que acolhemos de maneira acrítica, e a aceitamos com tanta força que resiste a qualquer refutação racional (BOBBIO, 2002).

Bobbio (2002) ressalta que o preconceito de grupo é geralmente um preconceito da maioria com relação a uma minoria e que suas consequências nocivas podem ser distribuídas em três níveis diversos, em razão do grau de gravidade. A primeira consequência é a discriminação jurídica, quando alguns passam a ser excluídos do gozo de certos direitos; posteriormente verifica-se a marginalização social, que se manifesta na formação de guetos e favelas que exclui determinados grupos do convívio social; e por fim, a perseguição política, em que se verifica o uso da força para esmagar uma minoria de desiguais.

A discriminação é entendida como uma diferenciação injusta, pois contraria a própria ideia de igualdade. Mas enquanto o preconceito é uma opinião, a discriminação é uma ação. Num primeiro momento, a discriminação se funda num juízo de fato, que é a mera constatação da diversidade. Num segundo momento, o juízo discriminante necessita de um juízo de valor, que considera um grupo 
superior e o outro inferior. Por fim, a discriminação se completa numa terceira fase, verdadeiramente decisiva, a qual implica o reconhecimento de que o grupo superior deve comandar ou dominar o inferior (BOBBIO, 2002).

Destaque importante merecem as desigualdades econômicas e sociais por contribuírem para uma preocupação geral com a intolerância e fomentarem práticas como o discurso de ódio. Os riscos associados aos discursos de ódio são particularmente mais agudos em tempos de crise econômica, já que é comum as pessoas procurarem um responsável pela perda de empregos ou instabilidade financeira (TSESIS, 2009).

"A intolerância é mais virulenta quando diferenças de cultura, etnia ou raça coincidem com diferenças de classe - quando membros de grupos minoritários também são subordinados economicamente" (WALZER, 1999, p. 74).

Redução de desigualdade entre os países e dentro deles passa, necessariamente, como uma medida para o combate a intolerância e manifestações de ódio.

O fortalecimento da democracia é também medida necessária de combate à intolerância, pois na democracia as "opiniões são livres e, portanto, são forçadas a se chocar, e ao se chocarem, acabam por se depurar. Para se libertarem dos preconceitos os homens precisam antes de tudo viver numa sociedade livre (BOBBIO, 2002, p. 118)".

Segundo Habermas (2002) os Estados democráticos de direito possuem diversos caminhos para a inclusão de minorias, especialmente através da concessão de autonomia cultural e políticas de equiparação. Sem que o preço seja a fragmentação da própria sociedade, as forças de coesão da cultura política comum precisam ser o denominador comum para que a nação de cidadãos não se despedace.

Na proposta de Bobbio (2002) não existe outra saída para combater o preconceito senão uma educação voltada para valores universais, isto porque a democracia inspira-se em princípios universais, como liberdade, justiça e tolerância e é inclusiva. $O$ autor reconhece, porém, que a educação não será suficiente se não transformada em ação correspondente. Instituições políticas e educação precisam caminhar juntas.

Por certo, os discursos de ódio podem ser desencorajados por uma educação universalista, mas não seria crível pensar que esta é uma solução definitiva e exclusiva. Nunca haverá uma sociedade completamente tolerante e mesmo os países mais liberais concordam que é preciso combater esse tipo de violência.

Entender que outras medidas se fazem necessárias, e qual a maneira mais adequada de estabelecer limites a um valor tão aclamado nas democracias como a liberdade de expressão, especificamente no que diz respeito ao discurso de ódio, é o que se fará a seguir. Para isso, buscouse o quanto já foi dito, no âmbito do sistema interamericano de proteção aos direitos humanos, pela Corte e pela Relatoria especial para Liberdade de Expressão; pela Corte Europeia de Direitos Humanos e pelo Conselho de Direitos Humanos da ONU.

\section{AS DIFERENTES REGULAMENTAÇõES E INTERPRETAÇÕES DO CONTEÚDO DA LIBERDADE DE EXPRESSÃO E DO DISCURSO DE ÓDIO}

Revista do Direito [ISSN 1982-9957]. Santa Cruz do Sul, v. 2, n. 55, p. 13-30, maio/ago. 2018. https://online.unisc.br/seer/index.php/direito/index 
A liberdade de expressão, enquanto direito reconhecido a todos os seres humanos, pode parecer ter um conteúdo unívoco. No entanto, não é o que acontece. Dentre as diferentes possibilidades de restrição da liberdade de expressão, não é diferente. A análise do caso do discurso de ódio é exemplo de que a depender de para onde o olhar se volte, o conteúdo do discurso de ódio e seus limites parecem se confundir. Por isso, há que se considerar as palavras em textos internacionais e as manifestações dos diferentes sistemas de proteção de direitos humanos, na tentativa de encontrar alguma formatação para o tratamento do discurso de ódio.

\subsection{Os sistemas de proteção de direitos humanos}

A partir das atrocidades e das claras violações aos direitos mais básicos do ser humano ocorridas durante a Segunda Guerra Mundial é que a comunidade internacional chega a um consenso sobre a necessidade de um sistema global de proteção aos direitos humanos. É no âmbito da Organização das Nações Unidas - ONU que a Comissão de Direitos Humanos, e a partir de 2006, - Conselho de Direitos Humanos, passou a desenvolver um trabalho de conscientização sobre a necessidade de atenção às violação de direitos humanos, assim como da construção de caminhos que possam levar ao maior respeito aos direitos consagrados internacionalmente.

Paralelo ao sistema global, surgem os sistemas regionais de proteção dos direitos humanos, com a missão de garantir maior proteção aos direitos humanos. Isso porque, o sistema global apresenta uma vulnerabilidade estrutural significativa (COELHO, 2008), na medida em que não existe um Tribunal Internacional de Direito Humanos e na medida em que as decisões, proferidas pelos órgãos das Nações Unidas, não possuírem um efeito jurídico vinculante (CORREIA, 2008).

A existência de sistemas regionais reforça os direitos humanos previstos nos tratados e declarações internacionais e é uma resposta para as dificuldades de implementação da defesa dos direitos humanos no âmbito global.

Nesse sentido, os sistemas global e regionais interagem para garantir uma maior proteção aos indivíduos, adotando o valor da dignidade humana como primazia e proporcionando a maior efetividade possível na tutela e promoção dos direitos fundamentais (PIOVESAN 2015). Atualmente, existem três sistemas regionais desenvolvidos: Europeu, Interamericano e Africano.

$\mathrm{Na}$ América, o sistema criado para promoção e proteção dos direitos humanos é o denominado Interamericano e funciona no âmbito da Organização dos Estados Americanos (OEA) e está assentado no trabalho realizado pela Corte Interamericana de Direitos Humanos e pela Comissão Interamericana de Direitos Humanos (COELHO, 2008).

A Convenção Americana de Direito Humanos, também conhecida como Pacto de San José da Costa Rica, instrumento de maior importância do sistema interamericano, foi subscrita após a Conferência Especializada Interamericana sobre Direitos Humanos, em 22 de novembro de 1969 na cidade de San José, Costa Rica e entrou em vigor em 1978. O Brasil somente ratificou a Convenção Americana de Direitos Humanos em 1992 e reconheceu a competência jurisdicional da Corte Interamericana em 1998, por meio do Decreto Legislativo n. 89 de 3 de dezembro. 
O texto da Convenção Americana inicia reafirmando a obrigação prevista na Carta da OEA de os Estados Partes se comprometerem com o respeito aos direitos e liberdades nela reconhecidos e a garantirem o seu livre e pleno exercício a toda a pessoa que esteja sujeita à sua jurisdição. Também, dedica a uma séria de direitos civis e políticos, tais como: direito à vida, à integridade pessoal, à liberdade pessoal, proteção da honra e dignidade, liberdade de consciência e de religião, à liberdade de pensamento e expressão, direito à nacionalidade, direito ao nome, direito à propriedade privada, entre outros.

A Convenção impõe ao Estado signatário a obrigação de adotar todas as medidas necessárias para o cumprimento das regras e obrigações assumidas. Ao reconhecer a competência da Corte Interamericana de Direitos Humanos assume o compromisso de cumprir com as decisões de um órgão jurisdicional não sujeito à sua soberania (CORREIA, 2008).

\subsection{O discurso de ódio nos diferentes sistemas}

São muitos os direitos previstos na Convenção Americana, e no que se refere ao direito à liberdade de pensamento e expressão, sua relevância é celebrada com a designação de uma Relatoria Especial para o tema, no âmbito da Organização dos Estados Americanos, em funcionamento desde 1997.

A Relatoria Especial para a liberdade de expressão foi estabelecida como um escritório permanente e independente que atua dentro do marco e com o apoio da Comissão Interamericana de Direitos Humanos. Suas atribuições principais são auxiliar a Comissão em casos individuais e preparar relatórios anuais sobre o tratamento dado ao direito à liberdade de expressão nos países membros da OEA e relatórios temáticos.

O direito à liberdade de pensamento e expressão está previsto no artigo 13 da Convenção, com a seguinte redação:

Artigo 13. Liberdade de pensamento e de expressão

1. Toda pessoa tem direito à liberdade de pensamento e de expressão. Esse direito compreende a liberdade de buscar, receber e difundir informações e ideias de toda natureza, sem consideração de fronteiras, verbalmente ou por escrito, ou em forma impressa ou artística, ou por qualquer outro processo de sua escolha.

Apresenta-se, da análise do citado artigo, duas dimensões da liberdade de expressão: uma individual e outra social. Em sua dimensão individual, a liberdade de expressão não se esgota no direito a falar e escrever, mas compreende o direito de utilizar qualquer meio apropriado para fazer difundir seu pensamento e chegar ao maior número de destinatários. Em sua dimensão social, a liberdade de expressão é um meio de intercâmbio de ideias e compreende o direito de cada um de comunicar seus pontos de vista e conhecer a opinião alheia (BRASIL, 2014).

As restrições ao exercício desse direito aparecem no artigo 13.2 e a Convenção deixa claro que os abusos à liberdade de expressão não podem ser objeto de medidas de controle preventivo, mas fundamento de responsabilidade para quem tenha cometido:

Revista do Direito [ISSN 1982-9957]. Santa Cruz do Sul, v. 2, n. 55, p. 13-30, maio/ago. 2018. https://online.unisc.br/seer/index.php/direito/index 
13. 2. O exercício do direito previsto no inciso precedente não pode estar sujeito a censura prévia, mas a responsabilidades ulteriores, que devem ser expressamente fixadas pela lei e ser necessárias para assegurar:

a. o respeito aos direitos ou à reputação das demais pessoas; ou

b. a proteção da segurança nacional, da ordem pública, ou da saúde ou da moral públicas.

Para que tal responsabilidade seja estabelecida é necessária: a existência de fundamentos de responsabilidade previamente estabelecidos; a definição expressa e taxativa desses fundamentos pela lei; a legitimidade dos fins perseguidos ao estabelecê-lo e que esses fundamentos sejam necessários para assegurar os mencionados fins (BRASIL, 2014).

As restrições indiretas constantes do 13.3 e 13.4 não se referem à liberdade de expressão pessoal, mas à atividade empresarial em matéria de imprensa, rádio e televisão (COMPARATO, 2010):

13. 3. Não se pode restringir o direito de expressão por vias ou meios indiretos, tais como o abuso de controles oficiais ou particulares de papel de imprensa, de frequências radioelétricas ou de equipamentos e aparelhos usados na difusão de informação, nem por quaisquer outros meios destinados a obstar a comunicação e a circulação de ideias e opiniões.

13. 4. A lei pode submeter os espetáculos públicos a censura prévia, com o objetivo exclusivo de regular o acesso a eles, para proteção moral da infância e da adolescência, sem prejuízo do disposto no inciso 2.

O parágrafo 5 do artigo 13 veda as expressões de ódio, já que os delitos contra a humanidade, com frequência, vêm acompanhados ou precedidos dessa forma de expressão (OEA, 2004). É aqui que se encontra o objeto principal do presente texto:

13. 5. A lei deve proibir toda propaganda a favor da guerra, bem como toda apologia ao ódio nacional, racial ou religioso que constitua incitação à discriminação, à hostilidade, ao crime ou à violência.

O direito à liberdade de pensamento e de expressão tem sido objeto de preocupação e estudo constante no âmbito do Sistema Interamericano em razão da sua importância para a proteção da autonomia individual e para a promoção da democracia.

Apesar do debate intenso sobre qual seria o objetivo mais importante da liberdade de pensamento e expressão, entende-se que esses dois objetivos são igualmente importantes e reforçam-se mutuamente (SARMENTO, 2007). Sem liberdades civis, como a liberdade de imprensa, de expressão, de reunião, a participação do povo no poder político é uma farsa, na mesma medida em que sem a participação popular no poder as liberdades civis têm pouca probabilidade de durar (BOBBIO, 1993).

Por certo, a liberdade de expressão está intimamente ligada ao desenvolvimento da autonomia do sujeito, na medida em que expressando suas opiniões, sentimentos e ideias e na troca com os demais, o sujeito toma consciência de si mesmo, de suas motivações e torna-se, portanto, mais autônomo.

Mas a liberdade de expressão é também "pedra angular na própria existência de uma sociedade democrática (BRASIL, 2014, p. 19)" na medida em que cada um possa participar da 
vontade do Estado. Assim, "[...] os direitos de liberdade foram desde o início a condição necessária para a direta aplicação das regras do jogo democrático [...] (BOBBIO, 2000, p.44)".

Dada a sua relevância para a democracia e o pluralismo político, a liberdade de expressão - pelo menos de acordo com significativa doutrina - assume uma espécie de posição preferencial (preferred position), quando da resolução de conflitos com outros princípios constitucionais e direitos fundamentais, muito embora se afirme que no Brasil a teoria da posição preferencial - em que pese consagrada pelo STF quando do julgamento da ADPF 130 - tem sido, em geral aplicada de forma tímida (SARLET, 2014, p. 446).

O relatório anual de 2015 da Relatoria para liberdade de expressão, ao tratar da violência crescente a comunidade LGBT, reforça que o art. 13 abarca o direito das pessoas de expressarem sua orientação sexual e identidade de gênero e que o direito a liberdade de expressão é fundamental para garantir o direito à igualdade das minorias e de grupos que tem sofrido discriminação histórica.

Trata-se ainda de direito fundamental também para viabilizar grupos vulneráveis a restabelecer o equilíbrio de poder entre os membros da sociedade, além do mais, promove a tolerância entre as culturas e favorece a desconstrução de estereótipos.

Discursos de ódio comumente de baseiam em estereótipos de grupos vulneráveis, a fim de influenciar um comportamento hostil em relação a eles. As declarações de supremacia negam a estes grupos o legítimo direito a igualdade e impedem sua participação na democracia (TSESIS, 2009).

As restrições ao exercício da liberdade de expressão previstas no item 5 do art. 13 da Convenção são as que mais interessam para o presente artigo e, na sequencia, é analisada a maneira com que o Sistema Interamericano as tratam.

Dentro de sua competência de redigir relatórios temáticos, a Relatoria para liberdade de expressão do Sistema Interamericano de Direitos Humanos, já em 2004, dedicou, no informe anual, um capítulo para tratar dos discursos de ódio. Antes dessa data nenhum relatório tratou do tema do discurso de ódio e após, em 2008, o relatório destacou um subtítulo para o tema e no relatório de 2015, aprovado pela Comissão Interamericana em 31 de dezembro do mesmo ano, o discurso de ódio volta a ter um papel central.

O Relatório de 2004 já afirmava que o manto da liberdade de expressão não é absoluto e que a Convenção Americana, assim como tantos outros tratados e pactos internacionais, declara que os discursos de ódio estão excluídos da proteção do art. 13. O relatório, em sua primeira parte, dedicou-se a realizar um estudo comparado e revelador de três princípios básicos que surgem da análise dos critérios adotados pelas Nações Unidas e pela Europa para caraterização do discurso de ódio.

Em primeiro lugar, o princípio central está relacionado ao propósito ou finalidade do discurso; deve ser avaliada a finalidade do discurso para sua configuração como discurso de ódio. Assim, mesmo quando são utilizadas expressões que indiquem o ódio em relação a um grupo, se se trata de uma investigação histórica ou se trata de transmitir uma informação, não há incitação ao ódio. 
Prevalece a boa-fé e, por isso, o discurso não pode ser condenado e prevalece a liberdade de expressão do indivíduo.

Em segundo, o contexto também é um aspecto importante na caracterização da expressão de ódio, dado que a mesma frase pode ter significados e consequências diferentes em contextos diferentes. $O$ que pode ser adequado em tempo de paz pode adquirir a condição de incitação à violência em tempos de guerra.

Por fim, não existe necessidade de um vínculo direto entre o discurso e a violência, isto porque, os efeitos danosos das expressões de ódio podem se projetar no tempo ou serem indiretos. Assim, mesmo que não ocorra um ato violento que possa ser vinculado ao discurso, ele pode configurar discurso de ódio.

O relatório afirma que a jurisprudência de outros sistemas pode servir de orientação, mas não para ampliar as restrições às liberdades garantidas aos indivíduos. A ressalva do relatório justifica-se, na medida em que a Corte, na Opinião Consultiva 05/85, já afirmava que as disposições da Convenção Americana são mais generosas com a liberdade de expressão na medida em que, ao impor restrições, apresentam redação mais específica. Enquanto 0 art. 13 da Convenção Interamericana detalha as possibilidades de restrição o art. $10^{4}$ da Convenção Europeia de direitos Humanos é genérico e não contém a proibição expressa de proibição de censura prévia constante do art. 13. Por isso, as limitações à liberdade de expressão da jurisprudência da ONU e da Corte Europeia devem ser utilizadas como padrões mínimos. Em outras palavras, o que o Relatório afirmava é que o instrumento americano delimita com maior precisão o que pode ser restrição à liberdade de expressão enquanto que o instrumento europeu deixa uma margem maior para aplicação de restrições.

Claramente existe uma abordagem diferente dos limites à liberdade de expressão nos países europeus e nos EUA, país que influenciou a redação da Convenção Americana, e que prioriza a liberdade de expressão sobre direitos contrapostos de dignidade, honra, civilidade e igualdade (BRUGGER, 2007). Segundo Rosenfeld (2001) enquanto a liberdade de expressão está fundada no individualismo e nas ideias libertárias nos EUA, em outras democracias ocidentais, como Canadá, Inglaterra e Alemanha, são valores como a honra, a dignidade, e o interesse coletivo que estão no coração das concepções sobre liberdade de expressão.

O relatório ainda ressalta que conforme redação do art. 13.5, a lei deve proibir toda forma de expressão que constitua incitação à violência ilegal. Portanto, a violência é requisito para qualquer restrição à liberdade de expressão. Já a Convenção Europeia admite as restrições que sejam

\footnotetext{
4 "Art. 10. 1. Qualquer pessoa tem direito à liberdade de expressão. Este direito compreende a liberdade de opinião e a liberdade de receber ou de transmitir informações ou ideias sem que possa haver ingerência de quaisquer autoridades públicas e sem considerações de fronteiras. O presente artigo não impede que os Estados submetam as empresas de radiodifusão, de cinematografia ou de televisão a um regime de autorização prévia.2. O exercício desta liberdades, porquanto implica deveres e responsabilidades, pode ser submetido a certas formalidades, condições, restrições ou sanções, previstas pela lei, que constituam providências necessárias, numa sociedade democrática, para a segurança nacional, a integridade territorial ou a segurança pública, a defesa da ordem e a prevenção do crime, a proteção da saúde ou da moral, a proteção da honra ou dos direitos de outrem, para impedir a divulgação de informações confidenciais, ou para garantir a autoridade e a imparcialidade do poder judicial". CORTE EUROPÉIA DE DIREITOS HUMANOS, 1951).
} 
necessárias em uma sociedade democrática e enumera fins como segurança nacional e integridade nacional como justificadores da limitação à liberdade de expressão.

Assim, as restrições à liberdade de expressão são mais restritas no Sistema Interamericano, que exige a incitação à violência ilegítima.

Para a Relatoria Especial para a liberdade de expressão, embora não exista uma definição universalmente aceita de discurso de ódio, seu conceito com frequência se refere a expressões a favor da incitação à violência com base na identificação da vitima como pertencente a determinado grupo social ou demográfico (OEA, 2015) ${ }^{5}$.

O discurso de ódio não pode abarcar ideias amplas e abstratas, como visões e ideologias políticas, a fé ou crenças pessoais. Nem se refere simplesmente a um insulto ou expressões injuriosas. No mais, os Estados estão obrigados a proibir o discurso de ódio quando o discurso constitua incitação à violência ou qualquer outra ação ilegal similar contra qualquer pessoa ou grupo de pessoas, por motivos que incluem raça, cor, religião, idioma, origem nacional, entre outros ${ }^{6}$.

Já as expressões ou comentários intolerantes que não constituem estritamente incitação à violência estarão sujeitos a responsabilidades posteriores nos moldes no art. 13.2. Tais responsabilidades ulteriores também deverão estar previstas em lei.

A Relatoria reconhece que representações negativas e outras expressões que estigmatizam as pessoas e determinados grupos, são ofensivas dolorosas e aumentam sua marginalização, mas pondera que a proibição a esse tipo de discurso não eliminará o estigma e o ódio profundamente arraigados nas sociedades na América. Pessoas que promovem esse tipo de discurso precisam ser refutadas e precisam ser persuadidos de seu erro no debate público, silenciá-las não diminui as desigualdades sociais estruturais e as visões discriminatórias. Nesse sentido é necessário garantir maior e melhor diversidade e pluralismo no acesso aos meios de comunicação ${ }^{7}$.

O Relatório Anual de 2015 preocupado com o aumento da violência a comunidade LGBT e sabendo que tal violência é reforçada pelos discursos de ódio dirigidos a estas pessoas, inicia afirmando em uma sociedade democrática os Estados devem proteger a liberdade de expressão ao mesmo tempo em que devem garantir a igualdade e segurança das demais pessoas.

O relatório demonstra ainda a preocupação com inciativas legais em vários países da América Latina que pretendem proibir o discurso de ódio mas acabam comprometendo o exercício do direito à liberdade de expressão.

\footnotetext{
5 Fica demonstrada aqui a diferença da abordagem do sistema interamericano que exige a violência como requisito para restrição à liberdade de expressão de outros conceitos que estendem também o discurso de ódio a expressões que alimentam um ambiente de intolerância. Brugger ao tratar do art. 130 do Código penal alemão informa que esse dispositivo tem por objetivo evitar um clima favorável ao crime de ódio. Não há necessidade de um risco presente para a punição. "Esse dispositivo é direcionado contra o "perigo de um perigo" (BRUGGER, 2007, p. 129).

${ }^{6}$ Há que se fazer a ressalva de que se a discussão se der sobre o texto da Convenção em língua portuguesa, a restrição à liberdade de expressão é maior, para abarcar o discurso que incite também à discriminação, à hostilidade ou ao crime. Além disso, a proibição está prevista nos textos em espanhol e português, no texto em inglês, a atuação estatal é posterior à ocorrência do discurso. 7 Volta-se aqui a ideia de educação universalista de Bobbio, como importante ferramenta para a criação de uma sociedade mais tolerante e inclusiva.
} 
Durante los últimos años, varios países de América han impulsado iniciativas legales para promover la igualdad, sancionar la discriminación y prohibir el "discurso de odio". Sin embargo, la CIDH há tomado conocimiento que en muchos casos esta legislación no satisface los principios de legalidad. La vaguedad de las definiciones que contienen podrían dar lugar a interpretaciones que comprometan el efectivo ejercicio de la libertad de expresión sobre asuntos de interés público (OEA, 2015, p. 373).

De toda forma, segundo o relatório, a Comissão e a Relatoria Especial reiteram que a promoção e proteção do direito a liberdade de expressão deve conjugar-se com esforços para combater a intolerância, a discriminação, o discurso de ódio e a incitação à violência (TSESIS, 2009).

Para que as sanções sejam possíveis nos discursos de ódio é preciso prova atual e objetiva de que a pessoa não estava simplesmente manifestando uma opinião, que tinha clara intenção de promover a violência ilegal ou qualquer outra ação similar, bem como a capacidade de atingir esse objetivo e que esse discurso signifique verdadeiro risco contra as pessoas que foram alvo do discurso.

O objetivo é traçar clara distinção entre o que será penalmente sancionado e os discursos que devem ser objeto de processo administrativo ou civil, na esteira do que já definido pelo Comitê de Direitos Humanos das Nações Unidas, em sua Recomendação Geral n. 35:

"El Comité recomienda que la tipificación como delito de las formas de
expresión racista se reserve para los casos más graves, que puedan
probarse más allá de toda duda razonable, mientras que los casos
menos graves deben tratarse por otros medios que no sean el
derecho penal, teniendo en cuenta, entre otras cosas, la naturaleza y
la amplitud de las repercusiones para las personas y los grupos
destinatarios. La aplicación de sanciones penales debe regirse por los
principios de legalidad, proporcionalidad y necesidad". Naciones
Unidas, Convención Internacional sobre la Eliminación de todas las
Formas de Discriminación Racial.

No sistema onusiano são considerados vários elementos que não estão previstos em nenhum documento internacional que trata sobre o tema. Por outro lado, como esse sistema envolve um número maior de países, as chances de se deparar com situações em que é debatida a extensão do direito da liberdade de expressão são maiores. Assim, ao contrário do que ocorre no sistema interamericano, a órgão das Nações Unidas e a Corte Europeia já tiveram a chance de se manifestar algumas vezes sobre o discurso de ódio, com base na Convenção Europeia de Direitos Humanos e no Pacto Internacional de Direitos Civis e Políticos. No âmbito americano, isso ficou a cargo, até então, da Relatoria especial, como se viu acima.

As Nações Unidas (2012) sugerem um teste de seis partes para que seja possível classificar o que deve ser criminalmente proibido. Deve ser analisado o contexto social e político em que o discurso foi feito e disseminado; deve ser levado em consideração o autor do discurso, sua posição ou status especialmente a posição dos organismos ou das pessoas dentro do contexto de a quem o discurso é dirigido. Deve ser analisado o objetivo do discurso, se está a fazer uma investigação histórica, de boa-fé, ou está transmitindo uma informação, ou se está fazendo apologia por exemplo, a intenção, assim, a negligencia e a imprudência não são suficientes para caracterizar 
discurso de ódio; o conteúdo também deve ser avaliado, no sentido de que a análise do discurso pode incluir o grau de provocação do discurso, o estilo, a natureza dos argumentos desenvolvidos, entre outros. Deve ainda ser avaliada a extensão do discurso, seus elementos, sua natureza pública, magnitude e tamanho da audiência. São elementos importantes o canal de transmissão, se um único folheto ou internet e a frequência, se o ambiente de divulgação era restrito ou aberto ao público em geral. Ainda, há que se considerar a probabilidade, a iminência eis que a incitação, por definição, é um crime incipiente. A ação que se defende através do discurso de incitação não precisa ser cometida para que esse discurso se constitua crime. No entanto, algum grau ou probabilidade de que aconteça deve ser identificado. Os tribunais devem determinar que havia uma probabilidade razoável do discurso ter sucesso no incitamento ao grupo alvo.

Por fim, a ONU destaca que as sanções penais devem ser medidas de último recurso aplicado apenas em situações estritamente justificáveis. Sanções civis e administrativas devem ser consideradas, incluindo reparações pecuniárias e direito de resposta.

Por fim, a Relatoria para liberdade de expressão aduz que todo limite a liberdade de expressão deve cumprir três garantias básicas: deve ser aplicada por um Poder Judiciário autônomo e independente; deve respeitar os princípios do devido processo legal e deve estar acompanhado de sanções proporcionais.

A tipificação penal deve seguir o estrito princípio da legalidade, com redação clara e sem ambiguidade, utilizando termos unívocos que limitem com precisão as condutas puníveis e suas respectivas penas.

A organização não-governamental Artigo 19 elaborou um documento, após reuniões com a ONU, diversas organizações, acadêmicos e sociedade civil, em Londres em 2008/2009, afirmando que os sistemas jurídicos devem deixar claro em suas legislações que ódio e hostilidade se referem a emoções intensas de afronta, inimizade ou aversão a um grupo objetivo; que o termo incitação se refere a declarações sobre grupos nacionais, raciais ou religiosos que podem criar um risco eminente de discriminação, hostilidade ou violência; que o termo promoção se entenderá como a intenção de promover publicamente o ódio.

Ponto importante de destaque no relatório de 2015 são os discursos de ódio advindos de funcionários públicos. Os funcionários públicos devem garantir que quando exercem sua liberdade de expressão não estão desrespeitando direitos humanos.

Nesse ponto o relatório cita $\circ$ Brasil e as expressões estigmatizantes e intolerantes advindas do Presidente da Comissão de Direitos Humanos da Câmara dos Deputados ${ }^{8}$. As autoridades devem se abster de difundir mensagens de ódio, bem como contribuir de maneira contundente a construção de um clima de tolerância e respeito, em que todos podem defender seus direitos, expressar seus pensamentos e opiniões.

Trata-se aqui, inclusive, da confiança que as pessoas depositam no Estado, que se vê mitigada por esse tipo de atitude. Uma sociedade pautada na tolerância e no pluralismo passa pelas

8 O relatório refere-se ao Deputado e pastor do PCS de São Paulo Marco Feliciano. Sob sua presidência foi aprovado na comissão o projeto conhecido como "Cura Gay", arquivado em julho de 2013 pela Mesa da Câmara. 
atitudes individuais, mas exige também um Estado atento a combater todo tipo de discurso de ódio, especialmente quando as mensagens intolerantes decorrem da fala dos seus representantes.

\section{CONTORNOS PARA APLICAÇÃO DA RESTRIÇÃO DO DISCURSO DE ÓDIO NO BRASIL}

E no Brasil? O país deverá enfrentar o mesmo dilema de outros países: em que extensão poderá restringir a liberdade de expressão, afirmando estar diante de discurso de ódio, sem afetar tão relevante direito?

O texto analisou a posição de Bobbio acerca da tolerância; a dicção dos instrumentos internacionais sobre a liberdade de expressão e o discurso de ódio e o quanto os organismos que lidam diuturnamente com os direitos humanos ainda tentam construir sobre a restrição ao direito dos indivíduos se expressarem para tentar resolver adequadamente casos concretos.

Os casos que chegam à análise dos organismos internacionais são aqueles em que o indivíduo entendeu que seu direito à liberdade de expressão não foi respeitado e que a restrição the imposta excedia o permitido pelos instrumentos internacionais.

O Brasil está sujeito à letra da Convenção Americana. Para além do que ela prescreve em seu artigo 13, especificamente em relação à liberdade de expressão, há que ser lembrado que outras disposições podem contribuir para resolver questões que sejam judicializadas.

O artigo 29 dita que "nenhuma disposição desta Convenção pode ser interpretada no sentido de ..... c) excluir outros direitos e garantias que são inerentes ao ser humano ou que decorrem da forma democrática representativa de governo..." ou no sentido de "d) excluir ou limitar o efeito que possam produzir a Declaração Americana dos Direitos e Deveres do Homem e outros atos internacionais da mesma natureza." O artigo XXVIII da Declaração Americana dos Direitos e Deveres do Homem, por sua vez, dita que: Os direitos do homem estão limitados pelos direitos do próximo, pela segurança de todos e pelas justas exigências do bem-estar geral e do desenvolvimento democrático." "išpi:Além disso, o artigo 32 estabelece que "os direitos de cada pessoa são limitados pelos direitos dos demais, pela segurança de todos e pelas justas exigências do bem comum, em uma sociedade democrática." Esses dispositivos indicam que a exigências das sociedades democráticas devem nortear a interpretação e a concretização dos direitos dispostos na Convenção Americana e, claro, de suas restrições. Isso não é novidade, a Corte Interamericana, na Opinião Consultiva $05 / 85$, que tratou sobre o registro profissional obrigatório de jornalistas, já declarou que "[A]s justas exigências da democracia devem, por conseguinte, orientar a interpretação da Convenção e, em particular, daquelas disposições que estão criticamente relacionadas à preservação e ao funcionamento das instituições democrática" (OPINIÂO CONSULTIVA, 5/85). [ičp?

Assim, sugere-se que a aplicação sistêmica da Convenção Americana ao Brasil resolva situações concretas. A proteção à liberdade de expressão é ampla nos instrumentos internacionais e as restrições aplicáveis devem levar em consideração o quanto é necessário para concretizar a democracia. Assim, caberá a cada Estado estabelecer o que significa a democracia e o fará conformando as liberdades e restringindo-as de acordo com a letra da Convenção e com suas regulamentações domésticas. $\mathrm{O}$ caso brasileiro não fugirá a esta regra. Contudo, há que se perceber

Revista do Direito [ISSN 1982-9957]. Santa Cruz do Sul, v. 2, n. 55, p. 13-30, maio/ago. 2018. https://online.unisc.br/seer/index.php/direito/index 
que a regra é elaborada de modo a deixar um espaço de decisão para o Estado. E este espaço será preenchido passo a passo, com as decisões proferidas em situações judicializadas. Assim, a cada nova movimentação do Judiciário para definir se um discurso está ou não conformado ao discurso de ódio, e para definir se a restrição que lhe é imposta está ou não de acordo com as disposições domésticas e a própria restrição que a regulamentação do discurso de ódio lhe impõe.

Assim, parece não haver dúvidas de que é correto defender a ideia de que em uma sociedade democrática como a brasileira, que busca a concretização da dignidade de todos, não há espaço para proteção de expressão que retire de grupos vulneráveis sua capacidade de participação democrática. Mas os limites para aplicação desta regra deverão ser testados e aplicados em cada caso concreto, com auxílio da avaliação dos elementos já sugeridos, como a autoria, o contexto, a finalidade e o objeto do discurso e sem perder de vista a sociedade democrática que cada Estado quer construir, na esteira da lição de Bobbio sobre a tolerância, no sentido de que devem ser toleradas todas as ideias, exceto aquelas que neguem a ideia mesma de tolerância.

\section{CONSIDERAÇÕES FINAIS}

Necessidade própria das sociedades democráticas atuais, diante do fenômeno da globalização e do encurtamento das fronteiras entre os Estados, é voltar suas discussões para mecanismos que garantam uma sociedade mais tolerante e inclusiva.

Palco de convívio de grupos social, econômico e culturalmente distintos, os Estados são os atores sociais primeiros que precisam garantir a possibilidade de pessoas e grupos tão distintos encontrarem espaço para manifestar suas crenças, tradições, ideias e opiniões.

Contudo, as sociedades democráticas, espaço próprio da coexistência pacífica de opiniões e interesses plurais e conflitivos, precisam encontrar uma mínima concordância sobre o que é tolerável ou intolerável, pois não podem permitir o preconceito e a discriminação, que minam a própria ideia de democracia e de ambiente plural.

Os Estados democráticos valorizam a liberdade de expressão como forma de manutenção desse espaço plural, mas proíbem, em maior ou menor medida formas de discurso que incitam a violência, discriminação ou preconceito. A liberdade de expressão, direito essencial para o desenvolvimento da autonomia individual e promoção da democracia, encontra limites.

O Brasil, enquanto membro do Sistema Interamericano de Diretos Humanos, está comprometido com decisões e recomendações do sistema, que em matéria de liberdade de expressão destaca especial importância, através da designação de uma Relatoria especial para liberdade de expressão.

Previsto no art. 13 da Convenção Interamericana de Direitos Humanos, o direito à liberdade de expressão e pensamento encontra suas limitações na própria redação do documento normativo.

A Convenção deixa claro que os abusos à liberdade de expressão não podem ser objeto de medidas de controle preventivo, mas fundamento de responsabilidade para quem tenha cometido. Para que tal responsabilidade seja estabelecida é necessária a existência de fundamentos de responsabilidade previamente estabelecidos; a definição expressa e taxativa desses fundamentos 
pela lei; a legitimidade dos fins perseguidos ao estabelecê-lo e que esses fundamentos sejam necessários para assegurar os mencionados fins.

O parágrafo 5 do artigo 13 veda os chamados discursos de ódio que se caracterizam por palavras que insultam, intimidam ou assediam pessoas ou grupos em virtude de sua raça, cor, etnicidade, nacionalidade, sexo ou religião e que têm a capacidade de incitar à discriminação, à hostilidade, ao crime ou à violência.

Para sua caracterização, partindo da análise dos relatórios anuais e temáticos promovidos pela Relatoria especial para liberdade de expressão, o discurso de ódio não pode abarcar ideias amplas e abstratas, nem se referir simplesmente a um insulto ou expressões injuriosas, mas deve constituir incitação à violência ou qualquer outra ação ilegal similar contra qualquer pessoa ou grupo de pessoas, por motivos que incluem raça, cor, religião, idioma, origem nacional, entre outros.

Embora não exista necessidade de um vínculo direto entre o discurso e a violência, isto porque, os efeitos danosos das expressões de ódio podem se projetar no tempo ou serem indiretos, a caracterização do discurso de ódio depende da existência de violência. Deve ser determinada uma probabilidade razoável de o discurso ter sucesso no incitamento à violência ao grupo alvo.

Apesar de todas estas inflexões sobre o tema, os casos concretos devem ser analisados individualmente, eis que não há uma regra geral para definir quando o discurso de ódio se faz presente. Ao contrário, há, sem dúvidas, alguns elementos que devem ser avaliados diante de cada ocorrência.

Para isso, o contexto definitivo em que deve ser inserido cada caso é o do regime democrático adotado pelo Brasil. Não somente porque a Constituição o demanda, mas também por que, como assinalado, a própria Convenção Americana de Direitos Humanos dá aos Estados espaço, com fundamento na democracia, para que formatem o conteúdo dos direitos e restrições ali previstos.

\section{REFERÊNCIAS}

Artigo 19. Los Principios de Camden sobre la Libertad de Expresión y la Igualdad. Abril de 2009. Disponível em: <https://www.article19.org/data/files/pdfs/standards/los-principios-de-camden-sobre-lalibertad-de-expresion-y-la-igualdad.pdf>. Acesso em 28 de julho de 2016.

Panorama sobre 0 discurso de ódio no Brasil. Disponível em: artig019.org/centro/files/discurso_odio.pdf. Acesso em: 19 de julho de 2016.

BECK. Ülrich. O que é globalização? Equívocos do globalismo: respostas à globalização. Tradução André Carone. São Paulo: Paz e Terra, 1999.

BRUGGER, Winfried. Proibição ou proteção do discurso do ódio? Algumas observações sobre o direito alemão e o americano. Revista Direito Público. Brasília: n. 15, jan./fev./mar de 2007.

BOBBIO, Norberto. A Era dos Direitos. Tradução Carlos Nelson Coutinho; apresentação Celso Lafer. 22 tir. Rio de Janeiro, Elsevier, 2004.

Igualdad y libertad. Barcelona: Ediciones Paidós, 1993.

Liberalismo e Democracia. São Paulo: brasiliense, 2000.

Revista do Direito [ISSN 1982-9957]. Santa Cruz do Sul, v. 2, n. 55, p. 13-30, maio/ago. 2018. https://online.unisc.br/seer/index.php/direito/index 
Elogio da Serenidade e outros ensaios. Trad. Marco Aurélio Nogueira. São Paulo: Editora Unesp. 2002.

BRASIL, Ministério da Justiça. Jurisprudência da Corte Interamericana de Direitos Humanos. Brasília: Ministério da Justiça, 2014.

CHÂTELET, François; DUHAMEL, Olivier; PISIER-KOUCHER, Evelyne. História das ideias políticas. Trad. Carlos Nelson Coutinho. Rio de Janeiro: Jorge Zahar, 1985.

COELHO, Rodrigo Meirelles Gaspar. Proteção internacional dos Direitos Humanos: A Corte Interamericana e a implementação de suas sentenças no Brasil. Curitiba: Juruá, 2008.

COMPARATO, Fábio Konder. A afirmação histórica dos Direitos Humanos. 7. ed. rev. e atual. São Paulo: Saraiva, 2010.

CORREIA, Thereza Rachel Couto. Corte Interamericana de Direitos Humanos: Repercussões jurídicas das opiniões consultivas. Curitiba: Juruá, 2008.

CORTE EUROPÉIA DE DIREITOS HUMANOS. Convenção para a proteção dos direitos do homem e das liberdades fundamentais de 1951. Disponível em: http://www.echr.coe.int/Documents/Convention_POR.pdf Acesso em: 5 de maio de 2016.

CORTE INTERAMERICANA DE DIREITOS HUMANOS. Opinião Consultiva 05/85. In Jurisprudência da Corte Interamericana de Direitos Humanos. Secretaria Nacional de Justiça, Comissão de Anistia, Corte Interamericana de Direitos Humanos. Tradução da Corte Interamericana de Direitos Humanos. Brasília: Ministério da Justiça, 2014.

HABERMAS, Jürgen. A inclusão do outro: estudos de teoria política. Trad. George Sperber e Paulo Astor Soethe. São Paulo: Edições Loyola, 2002.

ONU - ORGANIZAÇÃO DAS NAÇÕES UNIDAS. Convención Internacional sobre la Eliminación de todas las Formas de Discriminación Racial. Recomendación general № 35 La lucha contra el discurso de odio racista. 26 de setembro de 2013. Disponível em: <http://bibliotecadigital.indh.cl/handle/123456789/603>. Acesso em: 10 de julho de 2016.

ORGANIZACIÓN DE LOS ESTADOS AMERICANOS. Comisión Interamericana de Derechos Humanos. Relatoría Especial para la Libertad de Expresión. Marco juridico interamericano sobre el derecho de libertad de expresión. Washington, D.C., 2010. Disponível em: < http://www.corteidh.or.cr/tablas/26833.pdf. Acesso em: 02 de fevereiro de 2016.

Comisión Interamericana de Derechos Humanos. Relatoría Especial para la Libertad de Expresión. Informe Anual de la relatoria especial para la libertad de expresión. Disponível em: <http://www.oas.org/es/cidh/expresion/docs/informes/anuales/InformeAnual2015RELE.pdf>. Acesso em 21 de set de 2016

Comisión Interamericana de Derechos Humanos. Relatoría Especial para la Libertad de Expresión. Las expresiones de odio y la Convención Americana sobre Derechos Humanos. Disponível

<http://www.oas.org/es/cidh/expresion/docs/informes/odio/ExpresionesdeodiolnformeAnual2004-

2.pdf>. Acesso em: 21 set. 2015.

Comisión Interamericana de Derechos Humanos. Relatoría Especial para la Libertad de Expresión. Informe Anual de la relatoria especial para la libertad de expresión 2004. Disponível 
em:, http://www.oas.org/es/cidh/expresion/showarticle.asp?artID=459\&IID=2>. Acesso em: 10 de julho de 2016.

PIOVESAN, Flávia. Direitos Humanos e Justiça Internacional. 6. ed. rev., ampl. e atual. São Paulo: Saraiva, 2015.

REZEK, Francisco. Direito Internacional Público: curso elementar. 15. ed. ver. e atual. São Paulo: Saraiva, 2014

SARLET, Ingo Wolfgang. Direitos Fundamentais em espécie. In: SARLET, Ingo Wolfgang, MARINONI, Luiz Guilherme. MITIDIERO, Daniel. Curso de Direito Constitucional. 3. ed. São Paulo: Revista dos Tribunais, 2014.

SARMENTO, Daniel. Liberdade de expressão, pluralismo e o papel promocional do Estado. Revista Diálogo Jurídico. Salvador: n. 16, agosto de 2007.

SILVA, Rosane Leal da, et al. Discurso de ódio em redes sociais: jurisprudência brasileira. Revista Direito GV. São Paulo, jul./dez 2011.

ROSENFELD, Michel. Hate speech in constitutional jurisprudence: a comparative analysis. Cardozo Law School: Jacob Burns Institute for Advanced Legal Studies. N. 41, april 2001. Disponível em: <http://papers.ssrn.com/sol3/papers.cfm?abstract_id=265939>. Acesso em: 25 de julho de 2016.

TSESIS, Alexander. Dignity and Speech: the regulation of hate speech in a democracy. Wake Forest Law Review. Chicago, Vol. 44, 2009. Disponível em: <http://papers.ssrn.com/sol3/papers.cfm?abstract_id=1402908>. Acesso em 17 de junho de 2016.

UNITED NATION, Rabat Plan of Action on the prohibition of advocacy of national, racial or religious hatred that constitutes incitement to discrimination, hostility or violence. 5 de outubro de $2012 . \quad$ Disponível em: <http://www.ohchr.org/Documents/lssues/Opinion/SeminarRabat/Rabat_draft_outcome.pdf>. Acesso em: 28 de julho de 2016.

WALZER, Michael. Da tolerância. Trad. Almiro Pisetta. São Paulo: Martins Fontes, 1999.

WOLFF, Robert. Além da tolerância. In: WOLFF, Robert; MOORE JR., Barrington; MARCUSE, Herbert. Crítica da tolerância pura. Trad. Ruy Jungmann. Rio de Janeiro: Jorge Zahar, 1970.

COMO CITAR ESSE DOCUMENTO:

SANTANA, Anna Luisa Walter de; PAMPLONA, Danielle Anne. Os contornos possíveis do discurso de ódio no brasil: proposta a partir da convenção americana de direitos humanos. Revista do Direito, Santa Cruz do Sul, v. 2, n. 55, set. 2018. ISSN 1982-9957. Disponível em: <https://online.unisc.br/seer/index.php/direito/article/view/12048>. Acesso em: doi:https://doi.org/10.17058/rdunisc.v2i55.12048. 